\title{
RENAL DISEASE IN SYSTEMIC LUPUS ERYTHEMATOUS: ALL THAT GLITTERS IS NOT GOLD
}

\author{
Hafiz Waleed Khan, Abdul Rehman Arshad, Abdul Wahab Mir \\ Pak Emirates Military Hospital/National University of Medical Sciences (NUMS) Rawalpindi Pakistan
}

\begin{abstract}
Patients with systemic lupus erythematosus may occasionally develop renal pathology from causes unrelated to the underlying disease. We describe one such case. This 22-year-old lady, with past history of arthritis, presented with dyspnea and fever. She had clinical signs consistent with systemic lupus erythematosus. Echocardiogram revealed valvular regurgitation. Antibiotics were started for probable infective endocarditis. She developed acute kidney injury. This was initially attributed to lupus nephritis, but subsequently renal histopathology revealed acute interstitial nephritis. Renal functions normalized with oral prednisolone. This case highlights the fact that a broader differential diagnosis must always be considered even if the diagnosis is clear.
\end{abstract}

Keywords: Acute interstitial nephritis, Corticosteroids, Lupus nephritis, Vancomycin.

How to Cite This Article: Khan HW, Arshad AR, Mir AW. Renal Disease in Systemic Lupus Erythematous: All That Glitters is Not Gold. Pak Armed Forces Med J 2021; 71(6): 2257-2259. D Doi: https://doi.org/10.51253/pafmj.v71i6.3311

This is an Open Access article distributed under the terms of the Creative Commons Attribution License (https://creativecommons.org/licenses/by-nc/4.0/), which permits unrestricted use, distribution, and reproduction in any medium, provided the original work is properly cited.

\section{INTRODUCTION}

Systemic lupus erythematosus (SLE) is a multisystem disorder, with highest incidence in North America and lowest in Africa. ${ }^{1}$ Almost half of patients with SLE have renal involvement with or without glomerular manifestations. ${ }^{2}$ Occasionally, patients develop renal pathology from causes unrelated to SLE. This case describes a young female with SLE who developed acute kidney injury (AKI) secondary to acute interstitial nephritis (AIN) induced by antibiotics.

\section{CASE REPORT}

A 22-years-old female was admitted to Armed Forces Institute of Cardiology (AFIC) with exertional dyspnoea and high-grade fever for 2 weeks. There was no wheeze, orthopnoea or ankle swelling. Examination revealed murmurs of aortic and mitral regurgitation, confirmed by echocardiography. There were no vegetations. She had been having small joint polyarthralgia for last 4 years. She had hospital admission for delirium with psychotic features 3 years back. There was history of intermittent oral ulcers and photosensitivity. She was married for 3 years but had never conceived. Biochemical profile and urinalysis were normal. A probable diagnosis of infective endocarditis complicating rheumatic heart disease was considered, keeping in mind the history and physical findings. Intravenous ceftriaxone and vancomycin were started. On eighth

Correspondence: Dr Hafiz Waleed Khan, Department of Medicine, Pak Emirates Military Hospital, Rawalpindi Pakistan

Received: 26 Sep 2019; revision received: 31 Mar 2020; accepted: 19 Jun 2020 admission day, she developed non-oliguric AKI that continued to worsen despite stopping vancomycin. With negative serial blood cultures ruling out infective endocarditis, she was referred to Pak Emirates Military Hospital for workup of AKI.

At the time of admission to our hospital, she was pale with facial butterfly rash. Proximal interphalangeal joints and both wrist joints were slightly swollen and tender. Initial investigations revealed haemoglobin $9.9 \mathrm{~g} / \mathrm{dL}$, TLC $4.1 \times 10^{9} / \mathrm{L}$, urea $18.5 \mathrm{mmol} / \mathrm{L}$ and creatinine $308 \mathrm{umol} / \mathrm{L}$. Urinalysis showed proteins $(+)$, RBC's (5-6/HPF) and no eosinophiluria.

With clinical features suggestive of SLE and failure of renal functions to improve with cessation of vancomycin, AKI was initially attributed to lupus nephritis. She was started on hydroxychloroquine $(200 \mathrm{mg}$ $\mathrm{BD})$ and oral prednisolone $(60 \mathrm{mg} /$ day). Antibiotics were stopped as repeat blood cultures were negative. Further evaluation showed positive Antinuclear antibodies (ANA), Anti-double stranded DNA (Anti-dsDNA) antibodies (1:160 titres) and normal C3 (1.1 g/L) and C4 $(0.22 \mathrm{~g} / \mathrm{L})$ levels. Urinary protein excretion was 772 $\mathrm{mg} /$ day. Kidneys were normal in size and echogenecity and non-obstructed on ultrasound. Renal histopathology showed normal glomeruli, marked interstitial oedema and inflammatory infiltrates with mild patchy tubular atrophy and eosinophilic casts (Figure). Immunofluorescence was negative.

A final diagnosis of SLE and drug-induced AIN was made. She responded to oral prednisolone and renal functions normalized by tenth day of admission. 
Prednisolone was gradually tapered off over the next two months. She is under regular follow-up with nephrology and cardiology teams.

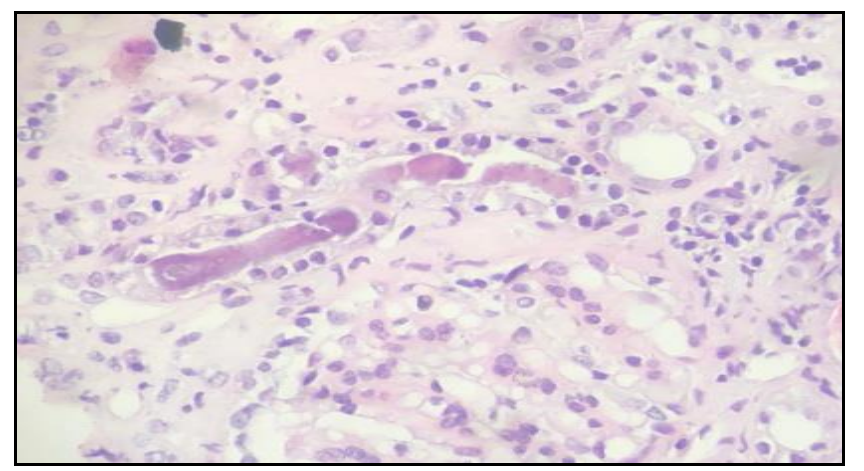

Figure: Histopathologic examination of renal biopsy specimen.

\section{DISCUSSION}

Though the diagnosis may seem straight forward, this case highlights the importance of thinking outside the box in routine clinical practice. Lupus nephritis is the first diagnosis coming to mind whenever any SLE patient develops renal problems. However, this patient had drug induced AIN. Tubulo-interstitial lupus nephritis was also considered in light of histopathology report was available. This is very rare and presents as AKI with no or mild proteinuria. ${ }^{3}$ Normal complements and negative immunofluore-scence effectively excluded this entity. This lady received antibiotics for a week. Once AKI developed, these were stopped. Nephrotoxicity of vancomycin is well recognized. It is seen in $10-40 \%$ cases and is due to oxidative stress. ${ }^{4}$ Concomitant use of nephrotoxic agents, increased duration of use and prolonged hospital stay are believed to increase the risk. ${ }^{5}$ In addition, list of drugs causing interstitial nephritis is quite extensive and includes $\beta$-lactam antibiotics like ceftriaxone. ${ }^{6}$ Naqvi et al, have previously documented their experience with drug induced interstitial nephritis at Karachi. ${ }^{7}$ Aminoglycosides and non-steroidal anti-inflammatory drugs were the most common culprits.

AIN is an immune-mediated hypersensitivity reaction. An inflammatory reaction is triggered after the exposure of the inciting agent leading to infiltration of neutrophils and the lymphocytes in the interstitium. The ensuing interstitial oedema and tubular damage can progress to tubular atrophy and interstitial fibrosis. ${ }^{8}$ AIN couldalso be secondary to infections or immune disorders. ${ }^{9}$ It is responsible for $15-20 \%$ cases of
AKI. ${ }^{10}$ This will become more common with increasing use of antibiotics and other medications.

Most important management step is to stop the causative agent. Patients not improving with this and those with other aetiologies generally require short courses of oral corticosteroids. ${ }^{6}$ Our patient was started on steroids considering the possibility of lupus nephritis, but once the diagnosis was clear, steroids were tapered off.

\section{CONCLUSION}

This case highlights the fact that a broader differential diagnosis must always be considered even if the diagnosis is clear. AIN is a reversible cause of AKI, so early suspicion and identification can prevent the progression to chronic kidney disease.

\section{Conflict of Interest: None.}

\section{Authors' Contribution}

HWK: Acquisition of data, drafting of article, final approval, ARA: Data analysis \& interpretation, drafting of article, AWM: Data analysis \& interpretation, critical revision, final approval.

\section{REFERENCES}

1. Rees F, Doherty M, Grainge MJ, Lanyon P, Zhang W. The worldwide incidence and prevalence of systemic lupus erythematosus: a systematic review of epidemiological studies. Rheumatol (Oxford) 2017; 56(11): 1945-1961.

2. Almaani S, Meara A, Rovin BH. Update on lupus nephritis. Clin J Am Soc Nephrol 2017; 12(5): 825-835.

3. Dhingra S, Qureshi R, Abdellatif A, Gaber LW, Truong LD. Tubulointerstitial nephritis in systemic lupus erythematosus: innocent bystander or ominous presage. Histol Histopathol 2014; 29(5): 553-565.

4. Elyasi S, Khalili H, Dashti-Khavidaki S, Mohammadpour A. Vancomycin-induced nephrotoxicity: mechanism, incidence, risk factors and special populations. a literature review. Eur J Clin Pharmacol 2012; 68(9): 1243-1255.

5. Bamgbola O. Review of vancomycin-induced renal toxicity: an update. Ther Adv Endocrinol Metab 2016; 7(3): 136-147.

6. Moledina DG, Perazella MA. PPIs and kidney disease: from AIN to CKD. J Nephrol 2016; 29(5): 611-616.

7. Naqvi R, Mubarak M, Ahmed E, Akhtar F, Naqvi A, Rizvi A. Acute tubulointerstitial nephritis/drug induced acute kidney injury; an experience from a single center in Pakistan. J Renal Inj Prev 2016; 5(1): 17-20.

8. Prendecki M, Tanna A, Salama AD, Tam FWK, Cairns T, Taube D, et al. Long-term outcome in biopsy-proven acute interstitial nephritis treated with steroids. Clin Kidney J 2017; 10(2): 233-239.

9. Kasper DL, Fauci AS, Hauser SL, Longo DL, Lameson JL, Loscalzo J. Harrison's Principles of Internal Medicine. New York, NY: McGraw-Hill Education; 2015, Available at: https:/ / accessmedicine.mhmedical.com/book.aspx?bookID=2129

10. Raghavan R, Eknoyan G. Acute interstitial nephritis-a reappraisal and update. Clin Nephrol 2014; 82(3): 149-162. 